\title{
Astragalus and Paeoniae Radix Rubra extract (APE) inhibits hepatic stellate cell activation by modulating transforming growth factor- $\beta /$ smad pathway
}

\author{
WEIJUAN HUANG ${ }^{1}$, LIN LI $^{1}$, XIAOPENG TIAN ${ }^{2}$, JINJIN YAN $^{3}$, XINZHENG YANG $^{3}$, \\ XINLONG WANG ${ }^{1}$, GUOZHEN LIAO ${ }^{1}$ and GENQUAN QIU ${ }^{4}$
${ }^{1}$ Department of Scientific Research, Xi'an Medical College, Xi'an, Shaanxi 710061; ${ }^{2}$ State Key Laboratory of Oncology
in South China, Collaborative Innovation Center of Cancer Medicine, Sun Yat-sen University, Guangzhou,
Guangdong 510060; ${ }^{3}$ Department of Pharmacology, Xi'an Medical College, Xi'an, Shaanxi 710061;
${ }^{4}$ Department of Traditional Chinese Medicine, First Affiliated Hospital of
Xi'an Jiao Tong University, Xi'an, Shaanxi 710061, P.R. China

Received February 15, 2014; Accepted November 7, 2014

DOI: $10.3892 / \mathrm{mmr} .2014 .3026$

\begin{abstract}
Previous studies have shown that Astragalus and Paeoniae Radix Rubra extract (APE) is capable of protecting against liver fibrosis in rats. The hypothesis of the present study was that APE exerts its anti-fibrotic effect by mediating the transforming growth factor $\beta$ (TGF- $\beta$ )/Smad signaling pathway. In order to investigate this hypothesis, a series of assays were designed to detect the effects of APE on cell proliferation, cell invasion and the activation of hepatic stellate cells (HSCs). In addition, the effects of APE on the TGF- $\beta /$ Smad signaling pathway were explored, with the aim of elucidating the underlying mechanisms. HSCs were initially isolated from normal rat liver. A number of assays were then employed in order to evaluate the effects of APE on the function of these cells. Cell proliferation was investigated using an MTT assay and cell invasion was observed with the use of transwell invasion chambers. Collagen synthesis was measured with a ${ }^{3} \mathrm{H}$-proline incorporation assay and expression of $\alpha$-smooth muscle actin was used to determine the extent of HSC activation. Protein expression induced by TGF- $\beta 1$ in HSCs was investigated by western blot and immunofluorescence analyses. Plasminogen activator inhibitor type1 (PAI-1) and urokinase-type plasminogen activator (uPA) transcriptional activity was measured using reverse transcription polymerase chain reaction. The results demonstrated
\end{abstract}

Correspondence to: Professor Genquan Qiu, Department of Traditional Chinese Medicine, First Affiliated Hospital of Xi'an Jiao Tong University, 227 Yanta West Road, Xi'an, Shaanxi 710061, P.R. China

E-mail: qiugenq@163.com

Key words: Astragalus and Paeoniae Radix Rubra extract, transforming growth factor- $\beta /$ smad pathway, plasminogen activator inhibitor type 1 , urokinase-type plasminogen activator that APE $(5-80 \mu \mathrm{g} / \mathrm{ml})$ significantly inhibited fetal bovine serum-induced cell proliferation in a dose-dependent manner. Cell invasion and activation of HSCs induced by TGF- $\beta 1$ were disrupted by treatment with APE in a dose-dependent manner. TGF- $\beta 1$ was observed to increase the phosphorylation of Smad2/3, while APE administered at higher doses produced inhibitory effects on Smad2/3 phosphorylation. In addition, administration of APE abrogated the TGF- $\beta 1$-induced reduction in Smad-7 expression in a dose-dependent manner. The results further indicated that APE treatment not only reduced PAI-1 expression, but also increased uPA expression in a dose-dependent manner. In conclusion, APE exerted inhibitory effects on cell proliferation, invasion and activation of HSCs, and the mechanisms underlying these effects may involve the TGF- $\beta 1 /$ Smad pathway.

\section{Introduction}

Hepatic fibrosis (HF) is recognized as one of the most common types of liver disease, as well as one that is resistant to the majority of current therapies, resulting in significant global morbidity (1). HF has been defined as a tissue-specific response to long-term injury or illnesses, including chronic viral hepatitis, alcoholic liver disease, cholestasis, circulatory disturbances, autoimmune liver disease or one of a number of nutritional disorders $(2,3)$. Liver fibrosis is characterized by the excessive deposition of extracellular matrix (ECM) proteins, consisting predominantly of type I and type III collagen. These abnormal depositions disturb the structure of the hepatic lobule, misdirecting blood flow in the liver and thereby disturbing its healthy functioning. This leads to liver cirrhosis and, ultimately, to liver carcinoma (4). Although numerous therapeutic options are currently available for liver fibrosis, all have limited degrees of success and none were capable of producing a complete cure (5). Thus, there is an urgent need to develop better preventative options as well as treatment approaches, based on a more thorough understanding of the pathogenesis of hepatic fibrosis. 
Although the exact pathophysiological mechanisms underlying the formation of hepatic fibrosis are elusive, there are a number of potential processes that may be worthy of investigation. Hepatic stellate cells (HSCs) are an important type of fibrogenic liver cell. They are found during liver injury and are known to be responsible for the progression of hepatic fibrosis (6). These cells may be activated, which induces their transdifferentiation into myofibroblasts (MFBs). MFBs are characterized by a number of fibrotic functions, including the induction of ECM deposition, $\alpha$-smooth muscle actin ( $\alpha$-SMA) expression, as well as the synthesis and secretion of type I and type III collagen $(7,8)$. A growing body of evidence has documented that inhibition of the transformation of HSCs may aid in the prevention and cure of liver fibrosis (9). However, HSCs are not the only mechanism through which fibrosis progresses. A number of studies have indicated that this process is complicated and involves numerous cytokines and signaling pathways $(10,11)$.

Transforming growth factor (TGF)- $\beta 1$ has been identified as the most significant factor involved in the activation and promotion of the transformation of HSCs (12). Previous studies have demonstrated that TGF- $\beta 1$ is highly expressed in numerous tissues, which exhibit fibrosis. Furthermore, TGF- $\beta 1$ has been shown to have a key role in the development of fibrosis by promoting the proliferation of tissue fibroblasts and the synthesis of collagen (13). The following stages of the cell-signaling pathway of TGF- $\beta 1$ have been elucidated: The initial step is the transmission of a signal from the activated transmembrane receptor, T $\beta R$. This signal is then transmitted to the nucleus, predominantly through intracellular members of the Smad family. Further evidence for this mechanism has been provided by studies in which the TGF- $\beta /$ Smad pathway was inhibited via RNA interference. This resulted in a significant decrease of type I and III collagen expression in fibrotic livers (14). Based on these findings, subsequent studies have confirmed the potential use of members of the Smad family as biomarkers with which to predict liver disease progression (15). Thus, the TGF- $\beta / \mathrm{Smad}$ pathway is hypothesized to be a target for the treatment and cure of hepatic fibrosis.

Astragalus and Paeoniae Radix Rubra extract (APE) is produced from a variety of herbs (Astragali Radix, Paeoniae Radix Rubra, Curcumae Rhizoma, Bupleuri Radix and Eupolyphaga) with a standard ratio of 30:30:15:12:10 by crude herb weight and contains the active components paeoniflorin, astragalosides and curzenone (16). Astragali Radix is thought to have restorative properties in Chinese Medicine, and studies have demonstrated that it is a hepatoprotective agent $(17,18)$. Extracts from Paeoniae Radix Rubra, Curcumae Rhizoma, Bupleuri Radix and Eupolyphaga also have the potential to suppress liver fibrosis and have been considered potent herbs with which to treat liver disease (19). Previous in vivo experiments have been conducted, which demonstrated that APE administered at a ratio of 30:30:15:12:10 exhibited superior antifibrotic effects compared to administration of individual herbs in a model of $\mathrm{CCl}_{4}$-induced chronic liver injury (16). However, the molecular mechanisms underlying the hepatoprotective effects of APE have remained elusive. Therefore, the present study aimed to investigate the effects of APE on proliferation, invasion and activation of
HSCs. In addition, the mechanisms underlying the effect of APE on the TGF- $\beta /$ Smad pathway were examined.

\section{Materials and methods}

Preparation of APE. The following herbs were purchased at Xi'an Chinese Medicine Corporation (Xi'an, China): Astragali Radix, Paeoniae Radix Rubra, Curcumae Rhizoma, Bupleuri Radix and Eupolyphaga. Each herb was identified by Dr Genquan Qiu, an author of the study and a specialist in Traditional Chinese Herbal Medicine. Herb samples were preserved in the specimen room of the Institute of Clinical Pharmacology at the Xi'an Medical College (Xi'an, China). The process of extracting and preparing the APE components from the five herbs was as follows: A total amount $8.45 \mathrm{~kg}$ dried sliced crude herbs (Astragali Radix, Paeoniae Radix Rubra, Curcumae Rhizoma, Bupleuri Radix and Eupolyphaga) in a standard ratio of 30:30:15:12:10 were decocted in 801 water three times at $95^{\circ} \mathrm{C}$ for $35 \mathrm{~min}$. The decocted solution was filtered though $150 \mu \mathrm{m}$ gauze ( Sigma-Aldrich, St. Louis, MO, USA) and the combined filtrates were then concentrated to a mass of $4.22 \mathrm{~kg}$ in a vacuum desiccator at $70^{\circ} \mathrm{C}$. The sediment was dried into power using a spray drier at a temperature range of $80-160^{\circ} \mathrm{C}$. This process yielded $2.11 \mathrm{~kg}$ of dry powder. It should be noted that in all subsequent in vitro cell experiments, APE powder was dissolved in Hank's solution (Sigma-Aldrich).

Cell culture. Male Sprague-Dawley rats were obtained from the Experimental Animal Center of Anhui Medical University (Anhui, China) and had a weight range of 160-200g. HSCs were separated from normal rat liver and maintained in Dulbecco's modified Eagle's medium (DMEM; Sigma-Aldrich), supplemented with $10 \%$ fetal bovine serum (FBS; Sigma-Aldrich) (20). Cells were cultured in an environment of $95 \%$ air and $5 \% \mathrm{CO}_{2}$ at $37^{\circ} \mathrm{C}$. All experiments were performed during the exponential growth phase, once the cells had been plated for $24 \mathrm{~h}$.

Cell proliferation assay. HSCs were seeded in 96-well plates at a density of $1 \times 10^{4}$ cells/well and cultured in $200 \mu \mathrm{l}$ DMEM supplemented with 10\% FBS. Following overnight starvation in serum-free medium, HSCs were incubated with $10 \%$ FBS with various concentrations of APE $(5,10,20,40$ or $80 \mu \mathrm{g} / \mathrm{ml})$ for $16 \mathrm{~h}$. Control conditions consisted of cells which had an equal volume of serum-free medium added without the addition of APE. Following incubation, cell proliferation was assessed using an MTT assay (Abcam, Cambridge, UK), as previously described (21). Absorbance was measured in an ELISA microplate reader at $562 \mathrm{~nm}$ (FlexStation 3; Molecular Devices, Sunnyvale, CA, USA). Data are expressed as the mean of a minimum of three independent experiments.

Cell invasion assay. Transwell invasion chambers with $8-\mu \mathrm{m}$ membrane pores coated with Matrigel ${ }^{\mathrm{TM}}$ (BD Biosciences, San Jose, CA, USA) were placed in 24-well plates. HSCs were starved overnight in serum-free DMEM. Cells were then seeded in the upper compartment of the chamber at a concentration of $1 \times 10^{5}$ cells/well and incubated with or without the administration of APE at various concentrations $(10,20,40$ or $80 \mu \mathrm{g} / \mathrm{ml})$ for $24 \mathrm{~h}$. Medium containing TGF- $\beta 1$ ( $40 \mathrm{pmol} / \mathrm{l})$ was 
placed into the lower compartment of the chamber. Serum-free medium was used for the control group. Following incubation, cells on the upper side of the membrane were completely removed using a cotton swab. Cells which had crossed the Matrigel barrier and migrated to the lower side of the chamber were fixed with $100 \%$ methanol for $1 \mathrm{~min}$ and stained with hematoxylin and eosin (H\&E; Sigma-Aldrich). The number of invading cells was counted in five randomly selected fields at x100 magnification (CX31; Olympus Corp., Tokyo, Japan). The mean number of invading cells in these fields was calculated and the experiments were run in triplicate.

Collagen synthesis assay. Collagen synthesis was evaluated using a ${ }^{3} \mathrm{H}$-proline incorporation assay (22). In brief, HSC cells were seeded in 96-well plates at a density of $1 \times 10^{4}$ cells per well for at least $24 \mathrm{~h}$. Cells were synchronized by culturing in serum-free medium overnight prior to incubation with $40 \mathrm{pmol} / 1 \mathrm{TGF}-\beta 1$ in the presence of APE at various concentrations $(10,20,40$ or $80 \mu \mathrm{g} / \mathrm{ml})$ for $24 \mathrm{~h}$. The control group received an equal volume of serum-free medium without APE. The aforementioned cultures were subsequently exposed to ${ }^{3} \mathrm{H}$-proline (37 kBq; Atom-Hitech, Beijing, China) for $12 \mathrm{~h}$. Following proline exposure, the cells were washed twice with phosphate-buffered saline (PBS; Sigma-Aldrich), treated with ice-cold 5\% trichloroacetic acid (Sigma-Aldrich) for $1 \mathrm{~h}$ and then washed twice more with distilled water. Finally, cells were lysed with $0.25 \%$ trypsogen and counted in a liquid scintillation counter (LS6000SE; Beckman Coulter, Fullerton, CA, USA).

Immunoblot analysis. HSCs were seeded at a density of $1 \times 10^{6}$ cells per dish. Once they reached sub-confluency, the cells were cultured in serum-free medium for $24 \mathrm{~h}$ in the presence or absence of APE at various concentrations $(10,20$ or $40 \mu \mathrm{g} / \mathrm{ml}$ ). Cells were then treated with $40 \mathrm{pmol} / \mathrm{l}$ TGF- $\beta 1$ for $30 \mathrm{~min}$. Control cells were treated with neither TGF- $\beta 1$ nor APE. Following incubation, cells were homogenized using a modified radioimmunoprecipitation assay buffer (50 mM Tris- $\mathrm{HCl}$, pH 7.4; 1\% NP-40; $150 \mathrm{mM} \mathrm{NaCl}$; and $1 \mathrm{mM}$ EDTA; Sigma-Aldrich) supplemented with protease and phosphatase inhibitors (1 $\mathrm{mM}$ phenylmethyl sulfonyl fluoride, $0.1 \mathrm{mM} N$-tosyl-L-phenylalanine chloromethyl ketone, $1 \mathrm{mg} / \mathrm{ml}$ aprotinin, $1 \mathrm{mg} / \mathrm{ml}$ pepstatin, $0.5 \mathrm{mg} / \mathrm{ml}$ leupeptin, $1 \mathrm{mM} \mathrm{NaF}, 1 \mathrm{mM} \mathrm{Na} \mathrm{P}_{2} \mathrm{O}_{4}$ and $2 \mathrm{mM} \mathrm{Na} \mathrm{VO}_{4}$ Sigma-Aldrich). The extract was centrifuged at $16,000 \mathrm{x} \mathrm{g}$ for 30 min at $4^{\circ} \mathrm{C}$ in order to remove cell debris. The supernatant was collected and quantified using the bicinchoninic acid protein assay (Pierce Biotechnology, Rockford, IL, USA) and boiled for $5 \mathrm{~min}$ with SDS sample buffer $(100 \mathrm{mM}$ Tris- $\mathrm{HCl}$, pH 6.8; $4 \%$ SDS; $12 \% \beta$-mercaptoethanol; $20 \%$ glycerol; and $0.01 \%$ bromophenol blue; Sigma-Aldrich) at the equivalent protein level. Samples were subjected to SDS-PAGE and transferred to polyvinylidene difluoride membranes (Bio-Rad Laboratories, Hercules, CA, USA). The membranes were then blocked with $10 \%$ skimmed milk powder (NanRong International Corp., Kaohsiung, Taiwan) in PBS containing $0.1 \%$ Tween-20 (Sigma-Aldrich) and incubated with the following primary antibodies: Mouse anti-human monoclonal antibodies against PAI-1 (1:2,000 mouse monoclonal, ab125687) and uPA (1:1,500, mouse monoclonal, ab82220), which were purchased from Abcam; mouse anti-human monoclonal antibodies against TGF- $\beta 1$ (1:1,000, mouse monoclonal, sc-130348) Santa Cruz Biotechnology, Inc., Dallas, TX, USA); rabbit anti-human phospho-Smad2 antibody (1:500, mouse monoclonal, BS3725), rabbit anti-human Smad2 antibody (1:500, mouse monoclonal, BS2993), rabbit anti-human phospho-Smad3 antibody (1:500, mouse monoclonal, BS4874), rabbit anti-human Smad3 antibody, (1:500, polyclonal, AP0446), rabbit anti-Smad7 antibody (1:500, polyclonal, BS60366) and rabbit anti- $\beta$-actin antibody (1:4,000, polyclonal, AP0060), which were purchased from Bioworld Technology (St. Louis, MO, USA); as well as rabbit anti- $\alpha$-SMA antibody $(1: 2,000$, polyclonal, BS70000; Cell Signaling Technology, Danvers, MA, USA), overnight at $4^{\circ} \mathrm{C}$. Following application of the primary antibodies, membranes were incubated with the appropriate secondary antibodies against mouse and rabbit (mouse $\operatorname{IgG}, 1: 2,000$, sc-2025; rabbit IgG 1:2,000, sc-2027; Santa Cruz Biotechnology, Inc.) for $2 \mathrm{~h}$ at room temperature. Finally, immunoreactivity was visualized using enhanced chemiluminescnce (Amersham Pharmacia Biotech, Picastaway, NJ, USA) and autoradiography. The resulting images were subjected to densitometric analysis using Quantity One software (Bio-Rad Laboratories).

Immunofluorescence. HSCs were seeded onto 24-well plates at $5 \times 10^{3}$ cells per well. Cells were then incubated in serum-free medium for $24 \mathrm{~h}$ with or without treatment with APE at various concentrations $(10,20$ or $40 \mu \mathrm{g} / \mathrm{ml})$ and stimulated with $60 \mathrm{pmol} / 1 \mathrm{TGF}-\beta 1$ for $1 \mathrm{~h}$. Control cells were incubated in serum-free medium with neither TGF- $\beta 1$ nor APE. Following incubation, cells were fixed with $4 \%$ paraformaldehyde for $30 \mathrm{~min}$, permeabilized and then blocked with $0.1 \%$ saponin and $0.5 \%$ bovine serum albumin (Sigma-Aldrich) in PBS for $30 \mathrm{~min}$ at $4^{\circ} \mathrm{C}$. Cells were incubated overnight at $4^{\circ} \mathrm{C}$ with the primary antibodies described above, and then incubated with fluorescein isothiocyanate-conjugated goat anti-rabbit immunoglobulin $\mathrm{G}$ (1:100) for $2 \mathrm{~h}$ at room temperature. Slides were then mounted with $80 \%$ phosphoglycerol, and visualized under a fluorescence microscope (CX31; Olympus Corp.). In each experiment, five randomly selected fields were analyzed from each sample.

Reverse transcription-polymerase chain reaction ( $R T-P C R)$. HSCs were seeded at $1 \times 10^{6}$ cells per dish. Cells were cultured in serum-free medium for $24 \mathrm{~h}$ with or without treatment with APE at various concentrations (10, 20 or $40 \mu \mathrm{g} / \mathrm{ml}$ ) treatment and stimulated with $10 \mathrm{pmol} / 1 \mathrm{TGF}-\beta 1$ for $3 \mathrm{~h}$ prior to harvesting. Control cells were cultured in an equal volume of serum-free medium without TGF- $\beta 1$ stimulation. The mRNA levels of HSCs were analyzed using an RT-PCR assay. Total sample mRNA was extracted using Trizol reagent (Invitrogen Life Technologies, Carlsbad, CA, USA) according to the manufacturer's instructions. Revert Aid First Strand cDNA Synthesis kit (Fermentas, Vilnius, Lithuania) was used to produce corresponding cDNA. The primers for plasminogen activator inhibitor type 1 (PAI-1), urokinase-type plasminogen activator (uPA) and $\beta$-actin (Sangon Biotech, Shanghai, China) were as follows: Forward, 5'-CGGAGCACGGTCAAGCAAGTG-3' and reverse, 5'-GTTGAGGGCAGAGAGAGGCGC-3' for PAI-1; 
Table I. Effects of APE on viability of HSCs treated with 10\% FBS.

\begin{tabular}{lccr}
\hline Group & APE dose $(\mu \mathrm{g} / \mathrm{ml})$ & Absorbance $\left(\mathrm{A}_{570}\right)$ & Inhibition $(\%)$ \\
\hline Control & - & $0.48 \pm 0.05$ & - \\
FBS $(12.5 \%)$ & - & $1.04 \pm 0.1^{\mathrm{c}}$ & 18.03 \\
APE & 5 & $0.91 \pm 0.07^{\mathrm{a}}$ & 29.46 \\
& 10 & $0.83 \pm 0.05^{\mathrm{a}}$ & 43.68 \\
& 20 & $0.73 \pm 0.04^{\mathrm{b}}$ & 78.42 \\
& 40 & $0.51 \pm 0.04^{\mathrm{b}}$ & 90.63 \\
\hline
\end{tabular}

${ }^{\mathrm{a}} \mathrm{P}<0.05 ;{ }^{\mathrm{b}} \mathrm{P}<0.01$, compared with model group; and ${ }^{\mathrm{C}}<0.01$, compared with control. Data are presented as the mean \pm standard deviation. APE, Astragalus and Paeoniae Radix Rubra; HSC, hepatic stellate cell; FBS, fetal bovine serum.
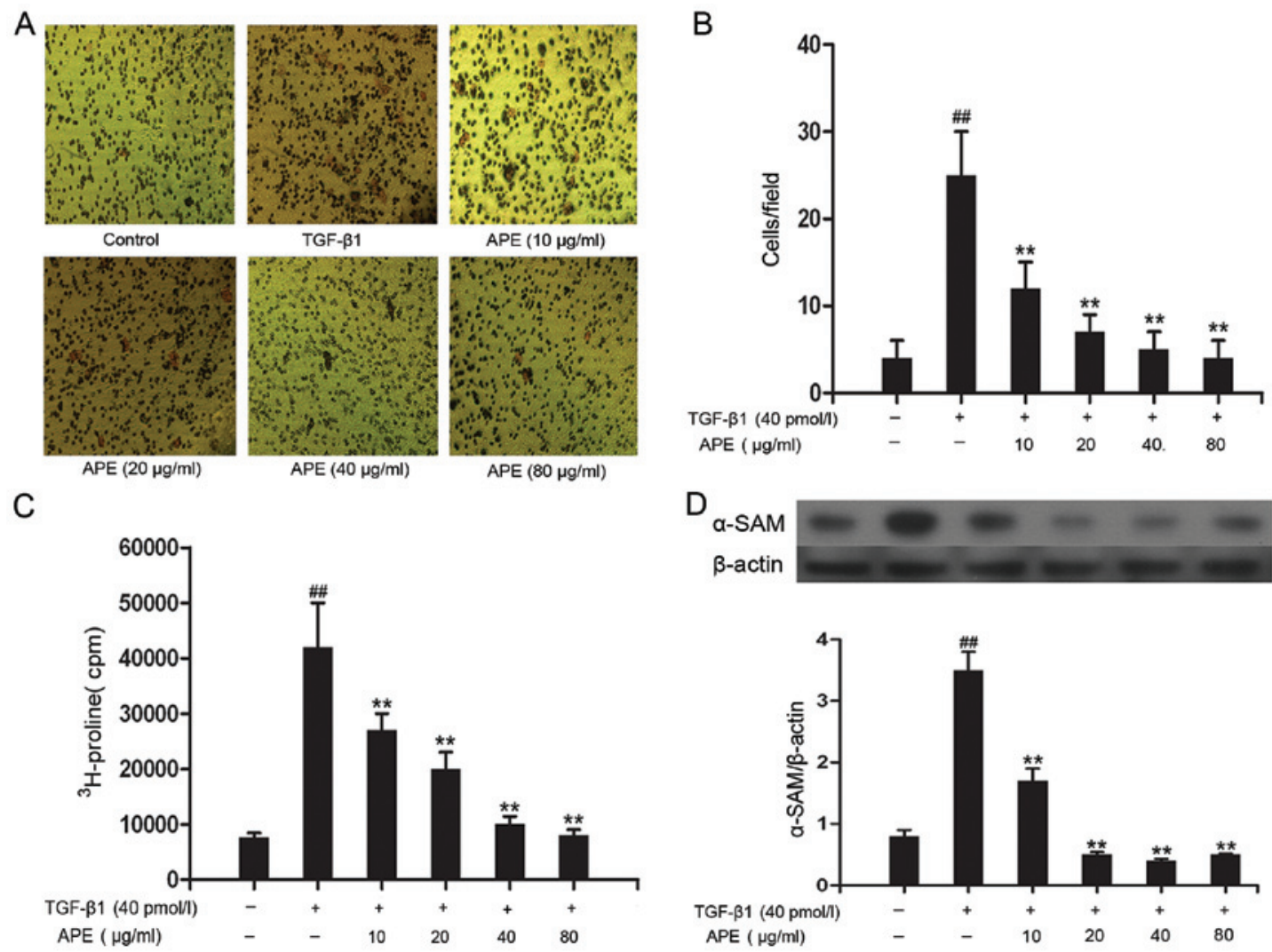

Figure 1. Effects of APE on TGF- $\beta 1$-induced invasion and activation of HSCs. (A and B) Number of cells resulting from stimulation of HSCs by TGF- $\beta 1$ treatment exhibited a significant, dose-dependent suppression when treated with APE (10, 20, 40 or $80 \mu \mathrm{g} / \mathrm{ml})$ (magnification, x100). (C) TGF- $\beta 1$-stimulated HSC collagen synthesis was significantly and dose-dependently decreased following treatment with APE (10, 20, 40 or $80 \mu \mathrm{g} / \mathrm{ml})$. (D) Expression of $\alpha$-SAM was significantly decreased following treatment with APE $(10,20,40$ or $80 \mu \mathrm{g} / \mathrm{ml})$ compared with that in the control. ${ }^{\# \#} \mathrm{P}<0.05$ compared with control group and ${ }^{* *} \mathrm{P}<0.05$ compared with group treated with TGF- $\beta 1$ alone. APE, Astragalus and Paeoniae Radix Rubra extract; TGF- $\beta 1$, transforming growth factor- $\beta 1$; $\alpha$-SAM, $\alpha$-sterile alpha motif; HSC, hepatic stellate cells.

forward, 5'-ACTACTACGGCTCTGAAGTCACCA-3' and reverse, 5'-GAAGTGTGAGACTCTCGTGTAGAC-3' for uPA; and forward, 5'-CTCCATCCTGGCCTCGCTGT-3' and reverse, 5'-GCTGTCACCTTCACCGTTCC-3' for $\beta$-actin. All target sequences were separately amplified for $30-35$ cycles of $30 \mathrm{sec}$ at $94^{\circ} \mathrm{C}, 30 \mathrm{sec}$ at $55^{\circ} \mathrm{C}$ and $60 \mathrm{sec}$ at $72^{\circ} \mathrm{C}$. Samples of each reaction product were separated by agarose gel electrophoresis (Sigma-Aldrich), visualized by ethidium bromide staining (Sigma-Aldrich) and visualized using $290 \mathrm{~nm}$ ultraviolet illumination (E1617-T130; Bio-Rad
Laboratories). The density of each band was measured by densitometry using Quantity One 4.52 software (Bio-Rad Laboratories).

Statistical analyses. Statistical analysis was performed using SPSS software (SPSS standard version 17.0; SPSS, Inc., Chicago, IL, USA). Data are expressed as the mean \pm standard deviation. Comparisons between groups were made using Student's t-test and the Mann-Whitney rank sum test, the latter of which was used to compare the degree of staining intensity. 

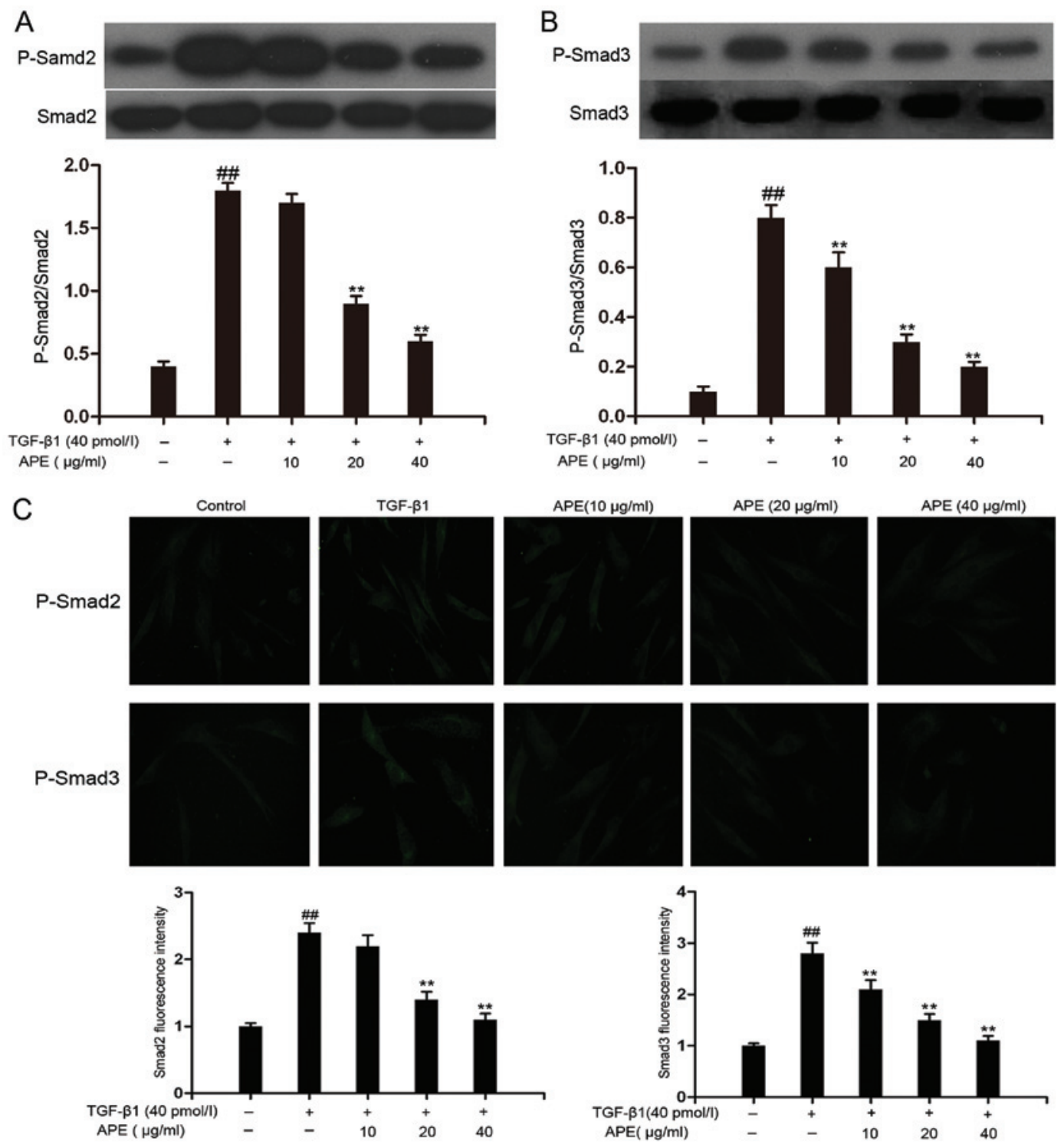

Figure 2. Effects of APE treatment on TGF- $\beta 1$-dependent Smad2 and Smad3 phosphorylation in HSCs. (A) TGF- $\beta 1$ significantly increased levels of Smad-2 phosphorylation, contrasting with the suppression of the Smad-2 phosphorylation following treatment with higher doses of APE (20 or $40 \mu \mathrm{g} / \mathrm{ml})$.(B) TGF- $\beta 1$ enhanced Smad-3 phosphorylation, and this increase was suppressed by treatment with APE (10, 20, $40 \mu \mathrm{g} / \mathrm{ml})$ in a dose-dependent manner. (C) Expression of phosphorylated R-Smad was elevated following TGF- $\beta 1$ treatment. Treatment with APE $(20,40 \mathrm{ug} / \mathrm{ml})$ significantly decreased the fluorescence intensity of phosphorylated Smad2 and Smad3 in a dose-dependent manner. ${ }^{\# \#} \mathrm{P}<0.05$ compared with control group and ${ }^{* *} \mathrm{P}<0.05$ compared with the group treated with TGF- $\beta 1$ alone. APE, Astragalus and Paeoniae Radix Rubra extract; TGF- $\beta 1$, transforming growth factor- $\beta 1$; HSC, hepatic stellate cells.

$\mathrm{P}<0.05$ was considered to indicate a statistically significant difference.

\section{Results}

APE suppresses HSC proliferation induced by FBS. In order to detect the effect of APE on HSCs proliferation, cells were stimulated with $10 \% \mathrm{FBS}$ and treated with varying concentrations of APE $(5-80 \mu \mathrm{g} / \mathrm{ml})$. As shown in Table I, $10 \%$ FBS increased the proliferation of HSCs, while the administration of APE $(5-80 \mu \mathrm{g} / \mathrm{ml})$ resulted in a suppression of HSC proliferation. The effect of APE-induced HSC suppression occurred in a dose-dependent manner, with an $\mathrm{IC}_{50}$ of $22.45 \mu \mathrm{g} / \mathrm{ml}$.

APE inhibits cell invasion induced by TGF- $\beta 1$. The invasion capability of HSCs was investigated using a Transwell inva- sion assay. As shown in Fig. 1A, HSCs moved to the lower compartment of the chambers across the Matrigel-coated polycarbonate membrane when stimulated by treatment with TGF- $\beta 1$. Treatment with APE $(10,20,40,80 \mu \mathrm{g} / \mathrm{ml})$ significantly reduced the number of TGF- $\beta 1$-stimulated cells that invaded across the polycarbonate membrane. In accordance with previous results, this effect occurred in a dose-dependent manner (23). Thus, TGF- $\beta 1$-induced HSC invasion into the bottom chamber and across the collagen IV/collagen I-coated polycarbonate membrane was inhibited by APE (Fig. 1A and B).

APE reduces TGF- $\beta 1$-induced HSC activation. Collagen synthesis was measured using a ${ }^{3} \mathrm{H}$-proline incorporation assay. As shown in Fig. 1C, collagen synthesis in TGF- $\beta 1$-stimulated HSCs was markedly increased compared with that of control 

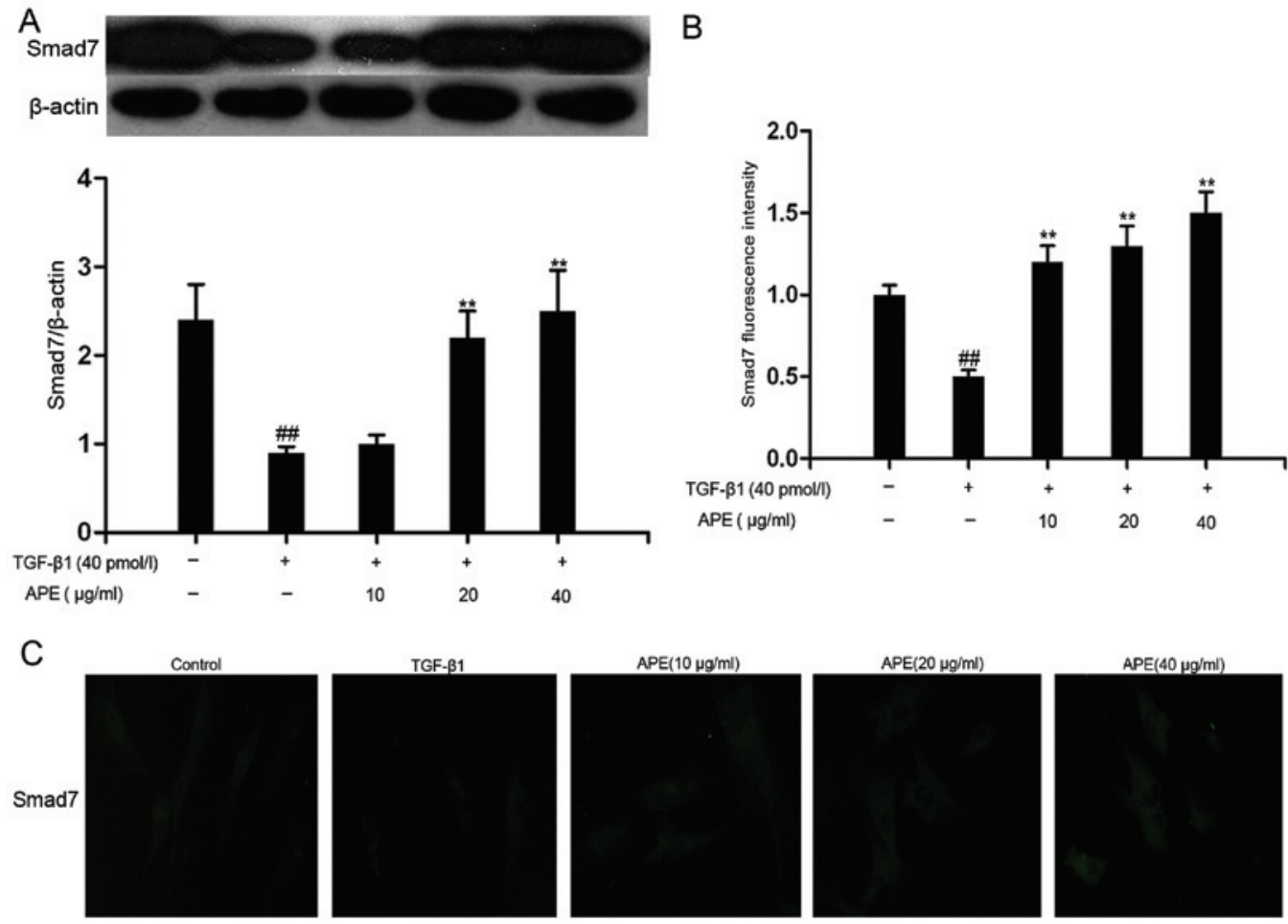

Figure 3. Effects of APE on TGF- $\beta 1$-induced reduction in Smad7 expression in HSCs. (A) Protein expression of Smad7 was significantly reduced following treatment with TGF- $\beta$ compared with that in controls. Higher doses of APE (20 or $40 \mu \mathrm{g} / \mathrm{ml}$ ) were shown to increase Smad7 expression. (B and C) TGF- $\beta 1$ decreased Smad7 fluorescence intensity, whereas higher doses of APE (20 or $40 \mu \mathrm{g} / \mathrm{ml})$ increased Smad7 fluorescence intensity. ${ }^{\# \#} \mathrm{P}<0.05$ compared with control and ${ }^{* *} \mathrm{P}<0.05$ compared with group treated with TGF- $\beta 1$ alone. APE, Astragalus and Paeoniae Radix Rubra extract; TGF- $\beta 1$, transforming growth factor- $\beta 1$; HSC, hepatic stellate cells.

cells $(\mathrm{P}<0.01)$. Furthermore, treatment with APE $(10,20,40$, $80 \mu \mathrm{g} / \mathrm{ml}$ ) significantly reduced TGF- $\beta 1$-induced collagen synthesis in a dose-dependent manner. Protein expression of $\alpha$-SAM was then used to measure HSC activation. As shown in Fig. 1D, the expression of the $\alpha$-SAM protein following treatment with TGF- $\beta 1$ alone was 3.5 -fold higher than that in the control group. Furthermore, administration of APE (10, 20,40, $80 \mu \mathrm{g} / \mathrm{ml}$ ) decreased $\alpha$-SAM expression in a dose-dependent manner. These results indicate that APE inhibits liver fibrosis by suppressing HSC activation and collagen synthesis.

APE reduces TGF- $\beta 1$-induced receptor regulated $(R)$-Smad phosphorylation in HSCs. R-Smad phosphorylation was detected by western blot and immunofluorescence analyses. As shown in Fig. 2A and B, western blotting results demonstrated that TGF- $\beta 1$ significantly increased the levels of Smad-2 phosphorylation and moderately enhanced Smad-3 phosphorylation. This increase in R-Smad phosphorylation was subsequently suppressed by the administration of APE $(20,40 \mu \mathrm{g} / \mathrm{ml})$ in a dose-dependent manner. Of note, a $10 \mu \mathrm{g} / \mathrm{ml}$ dosage of APE significantly reduced Smad-3, but not Smad-2 phosphorylation. Immunofluorescence also demonstrated that the expression of phosphorylated R-Smad was elevated as a result of TGF- $\beta 1$ treatment (Fig. $2 \mathrm{C}$ ). Treatment with APE $(20,40 \mu \mathrm{g} / \mathrm{ml})$ significantly reduced the fluorescence intensity of phosphorylated Smad2 and Smad3 in a dose-dependent manner. In accordance with the results from the western blotting experiments, a $10 \mu \mathrm{g} / \mathrm{ml}$ dosage of APE reduced the fluorescence intensity of phosphorylated Smad3, but had no detectable effect on that of phosphorylated Smad-2. These results indicated that APE decreased TGF- $\beta 1$-induced R-Smad phosphorylation.

APE enhances Smad7 expression in HSCs, reversing downregulation of Smad 7 by TGF- $\beta 1$. As shown in Fig. 3A, western blot analysis demonstrated that the protein expression of Smad7 was significantly reduced following treatment with TGF- $\beta 1$ compared with that in the controls. However, administration of high doses of APE (20 and $40 \mu \mathrm{g} / \mathrm{ml})$ was able to inverse this effect, leading to an increase in the expression of Smad7. Immunofluorescence demonstrated that TGF- $\beta 1$ reduced the fluorescence intensity of Smad7, whereas treatment with APE $(10,20$ or $40 \mu \mathrm{g} / \mathrm{ml})$ increased Smad7 fluorescence intensity (Fig. 3B and C). These results indicated that APE at high doses increased the expression of Smad-7.

APE suppresses PAI-1 and increases uPA expression, reversing the effects of TGF- $\beta 1$ on HSCs. As shown in Fig. 4A, protein expression of PAI-1 was markedly increased in HSCs treated with TGF- $\beta 1$ compared with that in the control group. However, treatment with APE (20 or $40 \mu \mathrm{g} / \mathrm{ml}$ ) suppressed protein expression in a dose-dependent manner. TGF- $\beta 1$ induced an increase of $\sim 3.5$-fold in PAI- 1 mRNA expression compared with controls, while APE suppressed the transcriptional activity of PAI-1 is a dose-dependent manner. This inhibitory effect of APE was statistically significant at higher concentrations (20 and $40 \mu \mathrm{g} / \mathrm{ml}$; Fig. 4B). In accordance with these results, TGF- $\beta 1$ significantly reduced uPA protein levels in HSCs, while APE, at concentrations of 20 or $40 \mu \mathrm{g} / \mathrm{ml}$, completely restored uPA protein expression levels 

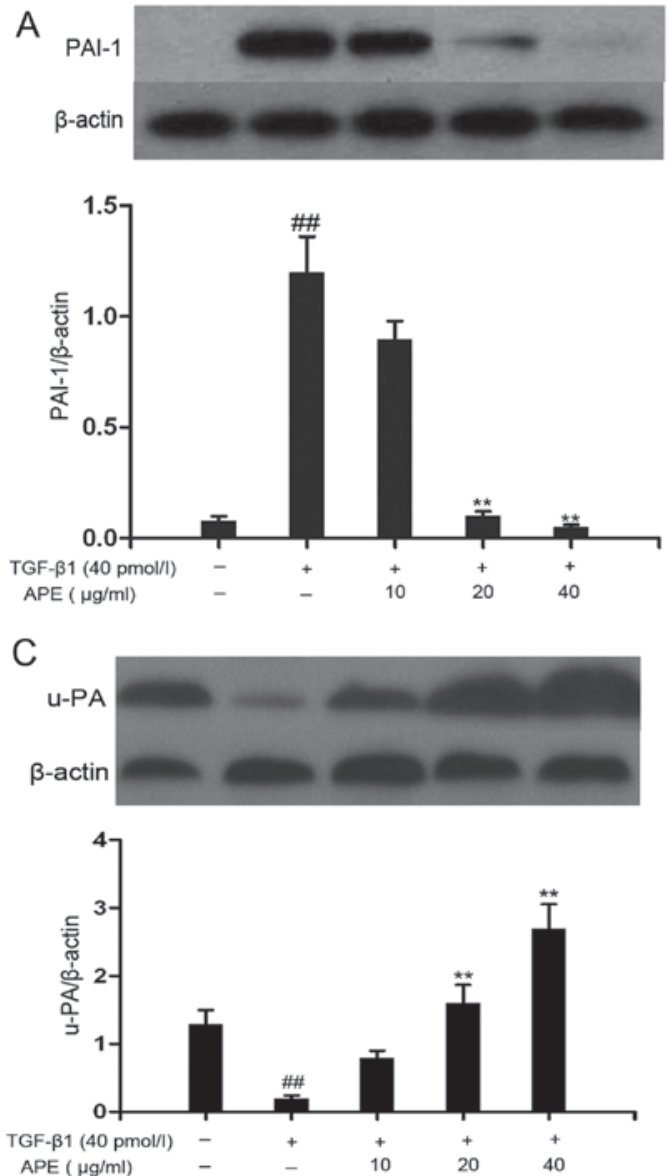

B
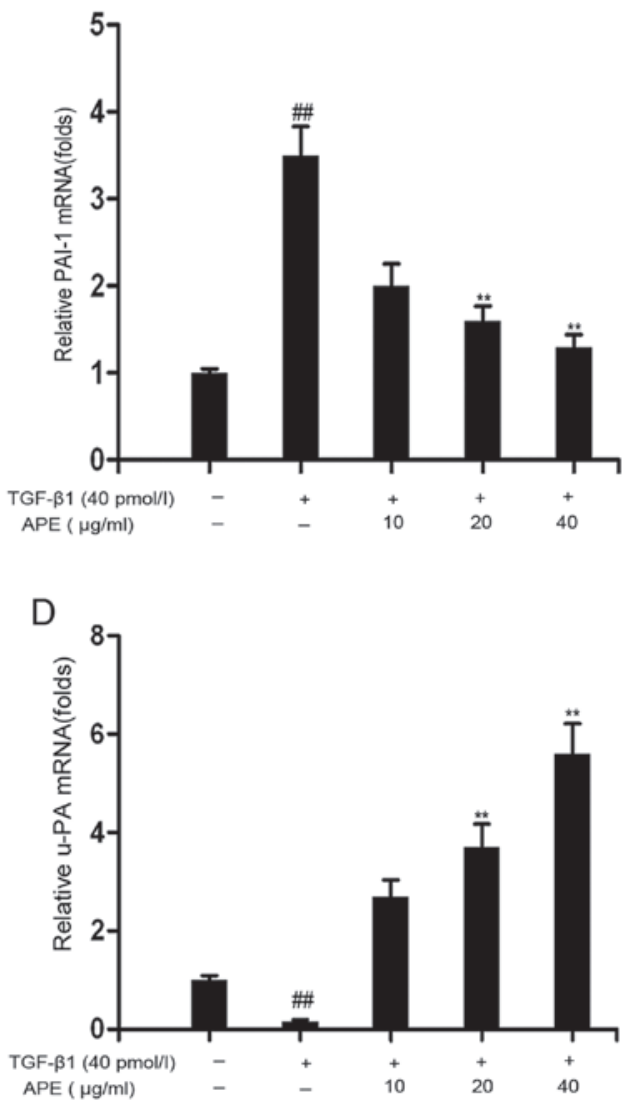

Figure 4. Effects of APE on PAI-1 and uPA in TGF- $\beta 1$-induced HSCs. (A) Protein expression of PAI-1 was markedly decreased in HSCs compared with that in controls treated with TGF- $\beta 1$ alone. APE treatment ( 20 or $40 \mu \mathrm{g} / \mathrm{ml}$ ) was shown to suppress protein expression in a dose-dependent manner. (B) TGF- $\beta 1$ treatment induced an increase of $\sim 3.5$-fold in PAI-1 mRNA expression compared with controls. Treatment with APE was found suppress the transcriptional activity of PAI-1 in a dose-dependent manner. (C) TGF- $\beta 1$ strongly decreased uPA protein levels in HSCs. Treatment with APE completely restored uPA protein expression at concentrations of either 20 or $40 \mu \mathrm{g} / \mathrm{ml}$. (D) The transcriptional activity of uPA was found to be lower following TGF- $\beta 1$ treatment. Application of APE at dosages of 20 and $40 \mu \mathrm{g} / \mathrm{ml}$ were found to increase mRNA levels of uPA. ${ }^{\# \#} \mathrm{P}<0.05$ compared with control and ${ }^{* *} \mathrm{P}<0.05$ compared with group treated with TGF- $\beta 1$ alone. APE, Astragalus and Paeoniae Radix Rubra extract; PAI-1, plasminogen activator inhibitor type 1; uPA, urokinase-type plasminogen activator; TGF- $\beta 1$, transforming growth factor- $\beta 1$; HSC, hepatic stellate cells.

in TGF- $\beta 1$-treated cells (Fig. 4C). The transcriptional activity of uPA was also reduced following TGF- $\beta 1$ treatment, while administration of APE at doses of 20 or $40 \mu \mathrm{g} / \mathrm{ml}$ resulted in an increase in uPA mRNA levels (Fig. 4D). These results demonstrated that APE treatment decreases PAI-1 expression and restores that of $\mathrm{UPA}$.

\section{Discussion}

Liver fibrosis is a chronic disease that is a culmination of the insidious effects of liver degeneration. In recent years, the clinical focus has concentrated predominantly on the prophylaxis and treatment of primary liver disease, including chronic hepatitis, or in trying to avoid contact with hepatotoxic substances (24-27). It has been shown that certain active components found in traditional herbal plants are effective in suppressing liver fibrosis and collagen synthesis, which indicated a potential therapeutic option for liver fibrosis (28-30). One of these studies demonstrated that APE significantly reduced levels of serum glutamic pyruvic transaminase, glutamic oxaloacetic transaminase and hydroxyproline in liver homogenates (31). Of note, APE also attenuated the pathological changes characteristic of liver fibrosis, which had been induced by $\mathrm{CCl}_{4}(16)$. In the present study, the results showed that APE markedly suppressed hepatic stellate cell proliferation and invasion, as well as their activation. Furthermore, these inhibitory effects may be due to the effects of APE on the TGF- $\beta /$ Smad pathway.

$\mathrm{HF}$ results from the excessive secretion of matrix proteins by HSCs, a process which is primarily triggered by TGF- $\beta 1$. A recent study suggested that garlic extract exhibits therapeutic effects in liver fibrosis through inhibition of TGF- $\beta 1$ in HSCs (32). Other studies have demonstrated that proanthocyanidin from grape seed extract exerts protective hepatocellular effects, which resulted in the amelioration of murine liver fibrosis, induced by TGF- $\beta 1$ (33). In addition, using TGF- $\beta 1$ small interfering RNA to inhibit the expression of TGF- $\beta 1$ attenuated rat hepatic fibrosis induced by a high-fat diet and $\mathrm{CCl}_{4}$ (34). The results of the present study confirmed that administration of TGF- $\beta 1$ significantly increased collagen synthesis in HSCs, which was hypothesized to be involved in the formation of liver fibrosis. APE suppressed the proliferation induced by FBS and the cell invasion induced by TGF- $\beta 1$ in HSCs in a dose-dependent manner. In addition, APE reduced 
the collagen synthesis and the expression of $\alpha$-SAM in HSCs, also in a dose-dependent manner. These results indicated that TGF- $\beta 1$ exerts pro-fibrotic activity in HSCs, primarily through a dual action of collagen synthesis promotion and the inhibition of collagen degradation. These combined effects ultimately lead to excessive collagen deposition.

TGF- $\beta 1$ controls a diverse set of cellular process and its canonical signaling is mediated via the TGF- $\beta$-induced phosphorylation of receptor-activated Smad2 and Smad3 (35). It was recently shown that the expression of the phosphorylated Smad2 and Smad3 proteins was higher in samples of $\mathrm{CCl}_{4}$-induced liver fibrosis, compared with that in the controls (36). Furthermore, overexpression of Smad ubiquitin regulatory factor 2 suppressed TGF- $\beta$-mediated liver fibrosis (37). Finally, co-treatment with Boswellia serrata and Salvia miltiorrhiza extracts reduced dimethylnotrosamine-induced hepatic fibrosis in mice via downregulation of phosphorylated Smad3 (38). The present study showed that APE inhibited the phosphorylation of Smad2 and Smad3 which was induced by TGF- $\beta 1$ in HSCs, in a dose-dependent manner. It was therefore hypothesized that the reduction of phosphorylated Smad 2 and -3 by APE may underlie its inhibitory effects on HSCs.

Smad7 serves as the negative feedback regulator for TGF- $\beta$ signaling, acting to antagonize the activity of the receptor-regulated Smads, which leads to a termination of the TGF- $\beta$ signal (39). Suppression of Smad7 by DNA methyltransferase 1 promoted the phosphorylation of Smad2 and Smad3 that had been induced by HSC activation, or liver fibrosis in general (40). Recent studies have shown that hepatocytes are more sensitive to the effects of TGF- $\beta$. This resulted in enhanced cell death in S7DeltaE1 and wild-type mice that had a deletion of exon I from the endogenous Smad7 gene. A study demonstrated that hepatocytes are more sensitive to the effects of TGF- $\beta$. In these mice, an increase in oxidative stress and an increase in cell damage in response to $\mathrm{CCl}_{4}$ was observed (41). Smad7-overexpression in common bile duct ligation rats reduced the expression of collagen and $\alpha$-SMA, as well as the hydroxyproline content in the liver (42). The present study also showed that TGF- $\beta 1$-induced reduction in Smad7 expression was ameliorated by treatment with APE in a dose-dependent manner. Smad7 has recently been used successfully to abrogate TGF- $\beta$ signaling in a number of fibrotic diseases, resulting in decreased collagen or $\alpha$-SMA expression as a result of inhibition of the phosphorylation of Smads (43). Therefore, it is possible that the inhibition of Smad activation caused by the application of APE may be partly due to an upregulation in Smad7 expression, with a resultant reduction in collagen production.

uPA and plasmin are involved in the cellular proteolytic degradation of ECM proteins and in the maintenance of tissue homeostasis. The activities of $\mathrm{uPA} /$ plasmin predominantly rely on the functioning of a potent inhibitor of PA, PAI-1 (44). Under normal physiological conditions, PAI-1 controls the activities of the uPA/plasmin system and thus maintains tissue homeostasis. Recently, a number of studies have demonstrated that co-expression of $\mathrm{Smad} 7$ and uPA attenuates $\mathrm{CCl}_{4}$-induced liver fibrosis in rats $(45,46)$. Furthermore, the administration of Genistein was shown to modify liver fibrosis and improve liver function by inducing uPA expression in $\mathrm{CCl}_{4}$-treated rats (47).
PAI-1 levels are known to be significantly elevated in fibrotic tissues and a lack of PAI-1 protects certain organs from fibrosis in response to injury-associated, pro-fibrotic signals (48). Liver fibrosis produces intrinsically high levels of PAI-1 and low levels of urokinase-type plasminogen activator. This altered ratio of activator and inhibitor activities is an important factor contributing to altered fibrin degradation and the subsequent ECM metabolism. The imbalance ultimately aids in the formation of liver fibrosis (49). In the present study, TGF- $\beta 1$ was shown to increase mRNA and protein levels of PAI-1 and decrease those of UPA, while APE significantly suppressed TGF- $\beta 1$-induced PAI-1 expression and increased uPA expression in the presence of TGF- $\beta 1$ in a dose-dependent manner, therefore reversing the effects of TGF- $\beta 1$. In view of growing evidence suggesting that elevated PAI-1 expression and reduced uPA expression are essential in collagen accumulation in HSCs, the APE-induced decrease in PAI-1 mRNA and protein expression may interfere with collagen deposition, thus preventing keloid formation.

In conclusion, the present study demonstrated that APE inhibited cell proliferation, invasion and collagen synthesis in HSCs, and that the mechanisms underlying these effects may involve the TGF- $\beta /$ Smad signaling pathway. These results provided evidence for the promising potential therapeutic use of APE in liver fibrosis.

\section{Acknowledgements}

The authors would like to thank Miss Yin Zhou and Mr. Xiaopeng Tian for their technical assistance, and the Department of Pathology at Peking University, Shen Zhen Hospital for providing and processing our samples. This study was supported by research grants from the Nature Science Foundation of Xi'an Medical College (grant no. L12C01).

\section{References}

1. Ray K: Liver: Hepatic stellate cells hold the key to liver fibrosis. Nat Rev Gastroenterol Hepatol 11: 74, 2014.

2. Kocabayoglu P and Friedman SL: Cellular basis of hepatic fibrosis and its role in inflammation and cancer. Front Biosci (Schol Ed) 5: 217-230, 2013.

3. Mello T, Ceni E, Surrenti C and Galli A: Alcohol induced hepatic fibrosis: role of acetaldehyde. Mol Aspects Med 29: 17-21, 2008.

4. Jian YC, Li W, He Y, Jiang M, Liu YB and Xiong WJ: Effect of oxymatrine on hepatic gene expression profile in experimental liver fibrosis of rats. Chin J Integr Med 18: 445-450, 2012.

5. Parise ER, de Oliveira AC, Conceicao RD, Amaral AC and Leite K: Response to treatment with interferon-alpha and ribavirin in patients with chronic Hepatitis $C$ virus genotypes 2 and 3 depends on the degree of hepatic fibrosis. Braz J Infect Dis 10: 78-81, 2006.

6. Tsolaki E, Athanasiou E, Gounari E, Zogas N, Siotou E, Yiangou M, Anagnostopoulos A and Yannaki E. Hematopoietic stem cells and liver regeneration: differentially acting hematopoietic stem cell mobilization agents reverse induced chronic liver injury. Blood Cells Mol Dis 53: 124-132, 2014.

7. Trebicka J, Hennenberg M, Odenthal M, et al: Atorvastatin attenuates hepatic fibrosis in rats after bile duct ligation via decreased turnover of hepatic stellate cells. J Hepatol 53: 702-712, 2010

8. Elsharkawy AM, Oakley F and Mann DA: The role and regulation of hepatic stellate cell apoptosis in reversal of liver fibrosis. Apoptosis 10: 927-939, 2005.

9. Moreira RK: Hepatic stellate cells and liver fibrosis. Arch Pathol Lab Med 131: 1728-1734, 2007.

10. Huang Q, Huang R, Zhang S, et al: Protective effect of genistein isolated from Hydrocotyle sibthorpioides on hepatic injury and fibrosis induced by chronic alcohol in rats. Toxicol Lett 217: 102-110, 2013. 
11. Su LJ, Chang CC, Yang CH, et al: Graptopetalum paraguayense ameliorates chemical-induced rat hepatic fibrosis in vivo and inactivates stellate cells and Kupffer cells in vitro. PLoS One 8: e53988, 2013.

12. Xu MY, Hu JJ, Shen J, Wang ML, Zhang QQ, Qu Y and Lu LG. Stat 3 signaling activation crosslinking of TGF- $\beta 1$ in hepatic stellate cell exacerbates liver injury and fibrosis. Biochim Biophys Acta 1842: 2237-2245, 2014.

13. Lang Q, Liu Q, Xu N, et al: The antifibrotic effects of TGF- $\beta 1$ siRNA on hepatic fibrosis in rats. Biochem Biophys Res Commun 409: 448-453, 2011.

14. Chen BL, Peng J, Li QF, Yang M, Wang Y and Chen W: Exogenous bone morphogenetic protein-7 reduces hepatic fibrosis in Schistosoma japonicum-infected mice via transforming growth factor-beta/Smad signaling. World J Gastroenterol 19: 1405-1415, 2013.

15. Lee JH, Lee H, Joung YK, et al: The use of low molecular weight heparin-pluronic nanogels to impede liver fibrosis by inhibition the TGF- $\beta /$ Smad signaling pathway. Biomaterials $32: 1438-1445$, 2011.

16. Hang W, Li L, Tian X, Yan J, Yang X, Wang X, Liao G1 and Qiu G. Astragalus and Paeoniae radix rubra extract inhibits liver fibrosis by modulating the transforming growth factor- $\beta / \mathrm{Smad}$ pathway in rats. Mol Med Rep: Nov 5, 2014 (Epub ahead of print)

17. Yu KZ, Liu J, Guo BL, et al: Microscopic research on a multi-source traditional Chinese medicine, Astragali Radix. J Nat Med 68: 340-350, 2013.

18. Yusufoglu HS, Alam A, Zaghloul AM, Al-Salkini MA and Alam P. Comparative anti-inflammatory and hepatoprotective activities of astragalus gummifer labill herb and roots in rats. Afr J Tradit Complement Altern Med 11: 268-274, 2014.

19. Liang J, Xu F, Zhang YZ, et al: The profiling and identification of the absorbed constituents and metabolites of Paeoniae Radix Rubra decoction in rat plasma and urine by the HPLC-DAD-ESI-IT-TOF-MS(n) technique: a novel strategy for the systematic screening and identification of absorbed constituents and metabolites from traditional Chinese medicines. J Pharm Biomed Anal 83: 108-121, 2013.

20. Knook DL, Seffelaar AM and de Leeuw AM: Fat-storing cells of the rat liver. Their isolation and purification. Exp Cell Res 139: 468-471, 1982

21. Majumdar M, Ratho R, Chawla Y and Singh MP. Evaluation of antigenicity and cell mediated immunity of hepatitis $\mathrm{E}$ virus patients: using non radioactive MTT assay. Indian J Med Microbiol 31: 64-68, 2013.

22. Zhou G, Kandala JC, Tyagi SC, Katwa LC and Weber KT: Effects of angiotensin II and aldosterone on collagen gene expression and protein turnover in cardiac fibroblasts. Mol Cell Biochem 154: 171-178, 1996.

23. Hu X, Rui W, Wu C, He S, Jiang J, Zhang X and Yang Y Compound Astragalus and Salvia miltiorrhiza extracts suppress hepatocarcinogenesis by modulating transforming growth factor- $\beta /$ Smad sigmaling. J Gastroenterol Hepatol 29: 1284-1291, 2014.

24. Hashiba M, Ono M, Hyogo H, et al: Glycemic variability is an independent predictive factor for development of hepatic fibrosis in nonalcoholic Fatty liver disease. PLoS One 8: e76161, 2013.

25. Hossain N, Afendy A, Stepanova M, et al: Independent predictors of fibrosis in patients with nonalcoholic fatty liver disease. Clin Gastroenterol Hepatol 7: 1224-1229, 2009.

26. Svegliati-Baroni G, Bugianesi E, Bouserhal T, et al: Post-load insulin resistance is an independent predictor of hepatic fibrosis in virus $\mathrm{C}$ chronic hepatitis and in non-alcoholic fatty liver disease. Gut 56: 1296-1301, 2007.

27. Kowdley KV, Belt P, Wilson LA, et al: Serum ferritin is an independent predictor of histologic severity and advanced fibrosis in patients with nonalcoholic fatty liver disease. Hepatology 55 77-85, 2012.

28. Chen HJ, Liang TM, Lee IJ, Huang YT and Lin YL: Scutellariae radix suppresses LPS-induced liver endothelial cell activation and inhibits hepatic stellate cell migration. J Ethnopharmacol 150: 835-842, 2013.
29. Katz TM, Goldberg LH and Friedman PM: Nonablative fractional photothermolysis for the treatment of striae rubra. Dermatol Surg 35: 1430-1433, 2009.

30. Zhou YX, Chen J, Li JP, Wang YL and Jin XD: Chinese medicinal herbs in treating model rats with hepatic fibrosis. Afr J Tradit Complement Altern Med 7: 104-108, 2010.

31. Vitcheva V, Simeonova R, Krasteva I, Nikolov S and Mitcheva M. Protective effects of a purified saponin mixture from Astragalus corniculatus Bieb., in vivo hepatotoxicity models. Phytother Res 27: 731-736, 2013.

32. D'Argenio G, Mazzone G, Ribecco MT, et al: Garlic extract attenuating rat liver fibrosis by inhibiting TGF- $\beta 1$. Clin Nutr 32: 252-258, 2013.

33. Li J, Li J, Li S, et al: Ameliorative effect of grAPE seed proanthocyanidin extract on thioacetamide-induced mouse hepatic fibrosis. Toxicol Lett 213: 353-360, 2012.

34. Lang Q, Liu Q, Xu N, et al: The antifibrotic effects of TGF- $\beta 1$ siRNA on hepatic fibrosis in rats. Biochem Biophys Res Commun 409: 448-453, 2011

35. Liu X, Yang Y, Zhang X, et al: Compound Astragalus and Salvia miltiorrhiza extract inhibits cell invasion by modulating transforming growth factor-beta/Smad in HepG2 cell. J Gastroenterol Hepatol 25: 420-426, 2010.

36. Tian XP, Yin YY and Li X: Effects and mechanisms of Acremoniumterricola milleretal mycelium on liver fibrosis induced by carbon tetrachloride in rats. Am J Chin Med 39: 537-550, 2011.

37. Cai Y, Zhou CH, Fu D and Shen XZ: Overexpression of Smad ubiquitin regulatory factor 2 suppresses transforming growth factor-beta mediated liver fibrosis. J Dig Dis 13: 327-334, 2012.

38. Sferra R, Vetuschi A, Catitti V, et al: Boswellia serrata and Salvia miltiorrhiza extracts reduce DMN-induced hepatic fibrosis in mice by TGF-betal downregulation. Eur Rev Med Pharmacol Sci 16: 1484-1498, 2012.

39. Freudlsperger C, Bian Y, Contag WS, et al: TGF- $\beta$ and NF-кB signal pathway cross-talk is mediated through TAK1 and SMAD7 in a subset of head and neck cancers. Oncogene 32: 1549-1559, 2013.

40. Bian EB, Huang C, Wang H, et al: Repression of Smad7 mediated by DNMT1 determines hepatic stellate cell activation and liver fibrosis in rats. Toxicol Lett 224: 175-185, 2014.

41. Hamzavi J, Ehnert S, Godoy P, et al: Disruption of the Smad7 gene enhances CCI4-dependent liver damage and fibrogenesis in mice. J Cell Mol Med 12: 2130-2144, 2008.

42. Dooley S, Hamzavi J, Breitkopf K, et al: Smad7 prevents activation of hepatic stellate cells and liver fibrosis in rats. Gastroenterology 125: 178-191, 2003.

43. Ji H, Tang H, Lin H, Mao J, Gao L, Liu J and Wu T. Rho/Rock cross-talks with transforming growth factor- $\beta / \mathrm{Smad}$ pathway participates in lung fibroblast-myofibroblast differentiation. Biomed Rep 2: 787-792, 2014.

44. Lin Z, Jiang L, Yuan C, et al: Structural basis for recognition of urokinase-type plasminogen activator by plasminogen activator inhibitor-1. J Biol Chem 286: 7027-7032, 2011.

45. Wang B, Li W, Chen Y, et al: Coexpression of Smad7 and UPA attenuates carbon tetrachloride-induced rat liver fibrosis. Med Sci Monit 18: R394-R401, 2012.

46. Tang LX, He RH, Yang G, Tan JJ, Zhou L, Meng XM, Huang XR and Lan HY. Asiatic acid inhibits liver fibrosis by blocking TGF-beta/Smad signaling in vivo and in vitro. PLoS One 7: e31350, 2012

47. Salas AL, Montezuma TD, Farina GG, Reyes-Esparza J and Rodriguez-Fragoso L: Genistein modifies liver fibrosis and improves liver function by inducing uPA expression and proteolytic activity in $\mathrm{CCl} 4$-treated rats. Pharmacology 81: 41-49, 2008.

48. Ghosh AK and Vaughan DE: PAI-1 in tissue fibrosis. J Cell Physiol 227: 493-507, 2012.

49. Tuan TL, Zhu JY, Sun B, Nichter LS, Nimni ME and Laug WE: Elevated levels of plasminogen activator inhibitor-1 may account for the altered fibrinolysis by keloid fibroblasts. J Invest Dermatol 106: 1007-1011, 1996. 